\title{
Can We Identify Patients with Microscopic Polyangiitis Who Are at Risk of Relapse?
}

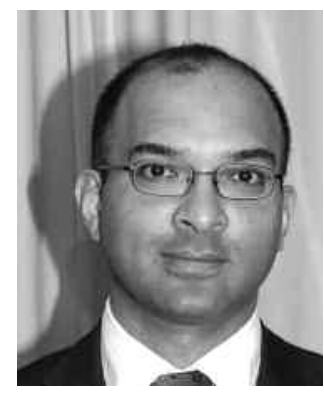

Microscopic polyangiitis (MPA) is an uncommon but not rare form of antineutrophil cytoplasm antibody (ANCA)-associated primary small-vessel vasculitis with a worldwide prevalence $^{1}$. Conventional treatment is cyclophosphamide (CYC) and glucocorticoids, without which mortality is very high ${ }^{2}$. The usual clinical presentation is significant renal disease; untreated it will lead to endstage renal failure in many cases ${ }^{3}$.

Early identification and treatment of MPA is important to prevent mortality but also in the hope of reducing longterm complications. Even with treatment, the vasculitides have a tendency to relapse $3,4,5,6,7,8,9$. The definition of relapse varies across studies, but this has been resolved to some extent by a consensus on conducting clinical trials in vasculitis ${ }^{10}$. Overall, the relapse rate can be up to $35 \%$ in ANCA-associated vasculitis, largely due to the very high rates of relapse in patients who have granulomatosis with polyangiitis (an extremely uncommon condition in Japan compared to Europe and North America ${ }^{1}$ ) but is reportedly much lower in MPA (around $8 \%{ }^{11}$ ). By contrast, mortality, particularly for severe disease, is around $24 \%-27 \%^{12}$.

In the current issue of The Journal, a group from Okayama, Japan, report on the risk factors associated with relapse ${ }^{13}$ in a retrospective study of a cohort of 62 patients with MPA. The most consistent finding was that rapid reduction of glucocorticoid therapy during the maintenance phase of treatment ( $>0.86 \mathrm{mg}$ per month) was a strong predictor for relapse. This is in keeping with a recent metaanalysis ${ }^{14}$ of 983 patients identified from previous studies. In the metaanalysis, patients who received a longer course of glucocorticoid therapy (more than 12 months) for their ANCA-associated vasculitis suffered fewer relapses than those given shorter courses (up to 12 months). However, the metaanalysis is inevitably weakened by the incomplete and variable description of the nature of relapses experienced by patients. Further, in the recent report of outcomes from a study looking at intravenous pulse high-dose CYC compared to continuous daily oral CYC in patients with ANCA-associated vasculitis ${ }^{9,15}$, although there was no difference in terms of mortality or renal impairment, relapse rates differed, being much greater in patients treated with pulse CYC (40\%) compared to continuous daily oral treatment $(21 \%)$. This was independent of glucocorticoid therapy because the glucocorticoid regimen was exactly the same in both arms. Of the original 149 patients included in the study, 71 had MPA, but the majority of relapses occurred in patients who were proteinase 3 (PR3) ANCA-positive.

By contrast, in the study by Wada, et $a l^{13}$, the mortality of patients was low (only 6.5\%) in contrast with US, European, and previous Japanese data ${ }^{16}$. In the latter study ${ }^{16}$, which followed over 1700 patients with rapidly progressive glomerulonephritis (of whom around 19\% had MPA), the 6-month survival rates were between $73 \%$ and $82 \%$. In addition, $53 \%$ of cases were managed with glucocorticoids alone. This is at significant variance with standard management of MPA in Europe or the US, which would include use of $\mathrm{CYC}^{2}$. The overall relapse rate in the current Japanese study ${ }^{13}$ was $24 \%$, suggesting that relapse was precipitated by rapid reduction in glucocorticoid doses (by more than $0.8 \mathrm{mg}$ per month); while this was independent of the use of concomitant immunosuppressant agents, the absolute numbers of patients who received CYC in the study were small given that only half the patients were actually treated with concomitant immunosuppressant agents. Decisions to introduce cytotoxic agents were based on the level of disease activity at diagnosis as measured using a BVAS (Birmingham Vasculitis Activity Score ${ }^{17,18}$ ) of 10 points or more. In practice, patients who have rapidly progressive glomerulonephritis will always score a BVAS of at least 10 points. The definition of relapse used in the study was for at least one new item of BVAS. Of the cases, 14 were defined as having major relapse, whereas only one was defined as having minor relapse. Relapse occurred at around 21 months following initial treatment. There was an impressive 12-fold difference in relapse rate according to how rapidly glucocorticoids were withdrawn. It is not clear whether the patients who relapsed were the ones who had been treated with glucocorticoids alone (and by definition

See Risk factors for relapse in microscopic polyangiitis, page 545

Personal non-commercial use only. The Journal of Rheumatology Copyright (c) 2012. All rights reserved. 
had milder disease because their initial BVAS score would have been $<10$ ); therefore we can only speculate on what influence the CYC may or may not have had in controlling disease. As reported in previous studies, relapse was associated with increased cumulative damage as measured by the Vasculitis Damage Index ${ }^{19}$, although the amount of damage accumulating as a result of relapse was less than that achieved during the initial presentation, confirming previous findings ${ }^{20}$. Patients who relapsed were more likely to have myeloperoxidase (MPO)-ANCA (67\% of patients were MPO-positive vs $45 \%$ PR3-ANCA-positive, but this was not statistically significant, probably because of the low numbers); this contrasts with the much lower number of relapses (around 8\%) in MPA, as reported ${ }^{11}$. A metaanalysis of 18 studies examining the relationship of ANCA status to relapse reported that a rise in ANCA or persistence of ANCA titer during a period of clinical remission had only a modest predictive value for subsequent relapse ${ }^{7}$.

Overall, Wada and colleagues ${ }^{13}$ present a cohort of patients with MPA who were given relatively mild treatment, whose relapse rate was similar to that in other studies, and who accumulated damage subsequent to major relapses. We assume that more aggressive immunosuppression was then used in response to their relapse. It is possible that undertreatment, i.e., lack of use of concomitant immunosuppressant, may have contributed to the relapse risk; but, in keeping with other studies, glucocorticoids remain an important factor in protecting patients against relapse.

Because this was not a controlled trial, patients were treated individually, with wide variation in starting dose (20-60 mg per day). Therefore, we have to consider other influences relevant to the findings in the study, including duration of the induction phase, starting dose and reduction rate of glucocorticoids and use of concomitant immunosuppression during induction, starting dose of glucocorticoid therapy, and use of concomitant immunosuppression in the maintenance phase. The relatively small size of the cohort precludes this kind of detailed analysis, but it is useful to consider how these factors should be incorporated into future therapeutic studies in vasculitis.

Thus, despite their acute and cumulative toxicity, glucocorticoids remain part of the current therapeutic resources for treating ANCA-associated vasculitis. Meanwhile, the search must continue for therapeutic strategies in vasculitis that will reduce or eliminate our ongoing dependence on glucocorticoids.

RAASHID A. LUQMANI, DM, FRCP, FRCPE,

Professor of Rheumatology,

National Institute for Health and Research,

Musculoskeletal Biomedical Research Unit,

University of Oxford,

Oxford, UK

Address correspondence to Dr. Luqmani.

E-mail: Raashid.luqmani@ndorms.ox.ac.uk

\section{REFERENCES}

1. Fujimoto S, Watts RA, Kobayashi S, Suzuki K, Jayne DR, Scott DG, et al. Comparison of the epidemiology of anti-neutrophil cytoplasmic antibody-associated vasculitis between Japan and the U.K. Rheumatology 2011;50:1916-20.

2. Mukhtyar C, Guillevin L, Cid MC, Dasgupta B, de Groot K, Gross $\mathrm{W}$, et al. EULAR recommendations for the management of primary small and medium vessel vasculitis. Ann Rheum Dis 2009; 68:310-7.

3. Corral-Gudino L, Borao-Cengotita-Bengoa M, Del Pino-Montes J, Lerma-Márquez JL. Overall survival, renal survival and relapse in patients with microscopic polyangiitis: A systematic review of current evidence. Rheumatology 2011;50:1414-23.

4. Gayraud M, Guillevin L, le Toumelin P, Cohen P, Lhote F, Casassus $\mathrm{P}$, et al; French Vasculitis Study Group. Long-term followup of polyarteritis nodosa, microscopic polyangiitis, and Churg-Strauss syndrome: Analysis of four prospective trials including 278 patients. Arthritis Rheum 2001;44:666-75.

5. Booth AD, Almond MK, Burns A, Ellis P, Gaskin G, Neild GH et al. Pan-Thames Renal Research Group. Outcome of ANCA-associated renal vasculitis: A 5-year retrospective study. Am J Kidney Dis 2003;41:776-84.

6. Hiemstra TF, Walsh M, Mahr A, Savage CO, de Groot K, Harper L, et al. Mycophenolate mofetil vs azathioprine for remission maintenance in antineutrophil cytoplasmic antibody-associated vasculitis: A randomized controlled trial. JAMA 2010;304:2381-8.

7. Tomasson G, Grayson PC, Mahr AD, Lavalley M, Merkel PA. Value of ANCA measurements during remission to predict a relapse of ANCA-associated vasculitis - A meta-analysis. Rheumatology 2012;51:100-9.

8. Walsh M, Flossmann O, Berden A, Westman K, Höglund P, Stegeman C, et al; on behalf of the European Vasculitis Study Group. Risk factors for relapse of ANCA associated vasculitis. Arthritis Rheum 2011 Sep 27. [Epub ahead of print]

9. Harper L, Morgan MD, Walsh M, Hoglund P, Westman K, Flossmann $\mathrm{O}$ et al. Pulse versus daily oral cyclophosphamide for induction of remission in ANCA-associated vasculitis: Long-term follow-up. Ann Rheum Dis 2011 Nov 29. [Epub ahead of print]

10. Hellmich B, Flossmann O, Gross WL, Bacon P, Cohen-Tervaert JW, Guillevin L, et al. EULAR recommendations for conducting clinical studies and/or clinical trials in systemic vasculitis: Focus on anti-neutrophil cytoplasm antibody-associated vasculitis. Ann Rheum Dis 2007;66:605-17.

11. Mukhtyar C, Flossmann O, Hellmich B, Bacon P, Cid M, Cohen-Tervaert JW, et al. Outcomes from studies of antineutrophil cytoplasm antibody associated vasculitis: A systematic review by the European League Against Rheumatism systemic vasculitis task force. Ann Rheum Dis 2008;67:1004-10.

12. Jayne DR, Gaskin G, Rasmussen N, Abramowicz D, Ferrario F, Guillevin L, et al. Randomized trial of plasma exchange or high-dosage methylprednisolone as adjunctive therapy for severe renal vasculitis. J Am Soc Nephrol 2007;18:2180-8.

13. Wada T, Hara A, Arimura Y, Sada K, Makino H, and the Research Group of Intractable Vasculitis, Ministry of Health, Labor, and Welfare of Japan. Risk factors associated with relapse in Japanese patients with microscopic polyangiitis. J Rheumatol 2012;39: 545-51.

14. Walsh M, Merkel PA, Mahr A, Jayne D. Effects of duration of glucocorticoid therapy on relapse rate in antineutrophil cytoplasmic antibody-associated vasculitis: A meta-analysis. Arthritis Care Res 2010;62:1166-73.

15. de Groot K, Harper L, Jayne DR, Flores Suarez LF, Gregorini G, Gross WL, et al. Pulse versus daily oral cyclophosphamide for induction of remission in antineutrophil cytoplasmic antibody-associated vasculitis: A randomized trial. Ann Intern Med

Personal non-commercial use only. The Journal of Rheumatology Copyright (C) 2012. All rights reserved. 
2009;150:670-80.

16. Koyama A, Yamagata K, Makino H, Arimura Y, Wada T, Nitta K, et al. A nationwide survey of rapidly progressive glomerulonephritis in Japan: Etiology, prognosis and treatment diversity. Clin Exp Nephrol 2009;13:633-50

17. Luqmani RA, Bacon PA, Moots RJ, Janssen BA, Pall A, Emery P, et al. Birmingham Vasculitis Activity Score (BVAS) in systemic necrotizing vasculitis. Q J Med 1994;87:671-8.

18. Mukhtyar C, Lee R, Brown D, Carruthers D, Dasgupta B, Dubey S, et al. Modification and validation of the Birmingham Vasculitis Activity Score (version 3). Ann Rheum Dis 2009;68:1827-32.
19. Exley AR, Bacon PA, Luqmani RA, Kitas GD, Gordon C, Savage $\mathrm{CO}$, et al. Development and initial validation of the Vasculitis Damage Index for the standardized clinical assessment of damage in the systemic vasculitides. Arthritis Rheum 1997;40:371-80.

20. Exley AR, Carruthers DM, Luqmani RA, Kitas GD, Gordon C, Janssen BA, et al. Damage occurs early in systemic vasculitis and is an index of outcome. Q J Med 1997;90:391-9.

J Rheumatol 2012;39:455-7; doi:10.3899/jrheum.111602 